\title{
Risk Evaluation on UHV Power Transmission Construction Project Based on AHP and FCE Method
}

\author{
Huiru Zhao and Sen Guo \\ School of Economics and Management, North China Electric Power University, Beijing 102206, China \\ Correspondence should be addressed to Sen Guo; guosen324@163.com
}

Received 31 October 2013; Revised 24 December 2013; Accepted 25 December 2013; Published 16 January 2014

Academic Editor: Ching-Ter Chang

Copyright ( $) 2014$ H. Zhao and S. Guo. This is an open access article distributed under the Creative Commons Attribution License, which permits unrestricted use, distribution, and reproduction in any medium, provided the original work is properly cited.

\begin{abstract}
Ultra high voltage (UHV) power transmission construction project is a high-tech power grid construction project which faces many risks and uncertainty. Identifying the risk of UHV power transmission construction project can help mitigate the risk loss and promote the smooth construction. The risk evaluation on "Zhejiang-Fuzhou" UHV power transmission construction project was performed based on analytic hierarchy process (AHP) and fuzzy comprehensive evaluation (FCE) method in this paper. After the risk evaluation index system was built, the AHP was used to determine the weights of risk indicators, and the FCE method was to perform the risk evaluation. The evaluation result shows that (1) "Zhejiang-Fuzhou" UHV power transmission construction project has moderate risk, which indicates the occurrence probability of project risk is medium and the risk occurrence will cause general loss for project, (2) "society risk" has the highest level, and the next is "policy and law risk," "technique risk," "natural environmental risk," and "Management risk," respectively, and it should keep main eye on the social risk, policy and law risk, and technique risk. Finally, according to the risk evaluation result, the specific risk control recommendations were proposed for the smooth construction of this project.
\end{abstract}

\section{Introduction}

The energy resource distribution and energy consumption pattern in China are inconsistent. The regions with abundant energy resources are usually far from the economy-developed regions with large energy consumption [1]. Facing the current situations, such as the coal-dominated energy structure, reverse distribution between energy production and consumption, and the rapid development of renewable energy industry, China needs to build the strong power grid to realize the optimal configuration of different energy resources in larger area, and then the electricity demands of the social economic development as well as people's livelihood can be met. The current $500 \mathrm{kV}$ power grid in China is limited for the long-distance and large-volume electricity power transmission, and it is difficult to efficiently transmit the electricity power generated by the western hydropower base and the north coal-power base to the central and eastern regions of China. Therefore, to advance the harmonious development of both the economy and society, building the ultra high voltage (UHV) power transmission system with the transmission capacity of long distance, high capacity and low loss is of great importance, which can promote the intensification development of large-scale coal-power, hydropower and nuclear-power generation bases, optimize the energy production and consumption pattern, and enhance the safety and reliability of China's power grid [2].

In China, the UHV power transmission construction projects are dispersed in many areas, which will face many issues such as harsh natural environment, many participation partners, a lot of works high above the ground, and complicated local relationship. The UHV power transmission construction project is the combination of technological innovation and engineering construction, which has the characteristics of high technological requirement, heavy workload, and significant demonstration effect. Compared with the conventional construction projects, the UHV power transmission construction project faces more challenges and risks. Therefore, building the risk evaluation index system and evaluating the comprehensive risk of UHV power transmission construction project are quite necessary. To the best of our knowledge, many researchers who study the 
power project issues put their attentions on power generation projects [3-7], and some researchers evaluate the risk of ultra-deep scientific drilling project [8], underground mining project [9], PPP waste-to-energy incineration projects [10], intelligent software project [11], and so on. However, it is very regretful to find that the risk of UHV power transmission construction project has rarely been studied. The risk evaluation on UHV power transmission construction project can identify the risk of project and provide some suggestions for the risk management and control.

"Zhejiang-Fuzhou" UHV power transmission construction project is a key power grid project invested by the State Grid Corporation of China (SGCC), which plays an important role in keeping the power network operating in safe and stable condition, promoting the efficient utilization of China's energy, and advancing the regional economic development. The risk of "Zhejiang-Fuzhou" UHV power transmission construction project was evaluated by using analytic hierarchy process (AHP) and fuzzy comprehensive evaluation (FCE) method in this paper (the reason why weselected AHP and FCE method to perform the risk evaluation will be discussed in Section 4). The evaluation result can identify the risk level of this project, point out the key risk criteria that need to be paid more attention, and provide the basis for the recommendations of controlling the project risk.

The paper is organized as follows: Section 2 provides an overview of "Zhejiang-Fuzhou" UHV power transmission construction project, which lays the foundation for building the risk evaluation index system; Section 3 identifies the risk index of "Zhejiang-Fuzhou" UHV power transmission construction project by using Delphi method and builds the risk evaluation index system. The risk evaluation of "Zhejiang-Fuzhou" UHV power transmission construction project based on AHP and FCE method is performed in Section 4. Specific risk control recommendations are proposed in Section 5; Section 6 concludes this paper.

\section{Overview of "Zhejiang-Fuzhou" UHV Power Transmission Construction Project}

2.1. Project Profile. "Zhejiang-Fuzhou" UHV power transmission construction project is invested by the SGCC, which connects the $1000 \mathrm{kV}$ substation located in the north of Zhejiang province and $1000 \mathrm{kV}$ substation located in Fuzhou city (the provincial capital of Fujian), just as shown in Figure 1. This project will build three new UHV transformer substations and two $603 \mathrm{~km}$-length AC transmission lines. The static and dynamic investments of this project amount to 20.716 and 21.336 billion Yuan, respectively. The capital required in this project is composed of own fund and bank loan, which accounts for $20 \%$ and $80 \%$, respectively. As the legal representative, the SGCC is responsible for this project's construction, operation, and repayment of loan principal and interest. "Zhejiang-Fuzhou" UHV power transmission construction project is very urgent in terms of project duration, which plans to be put into operation during the "12th FiveYear Plan" period. If this project can be constructed and put

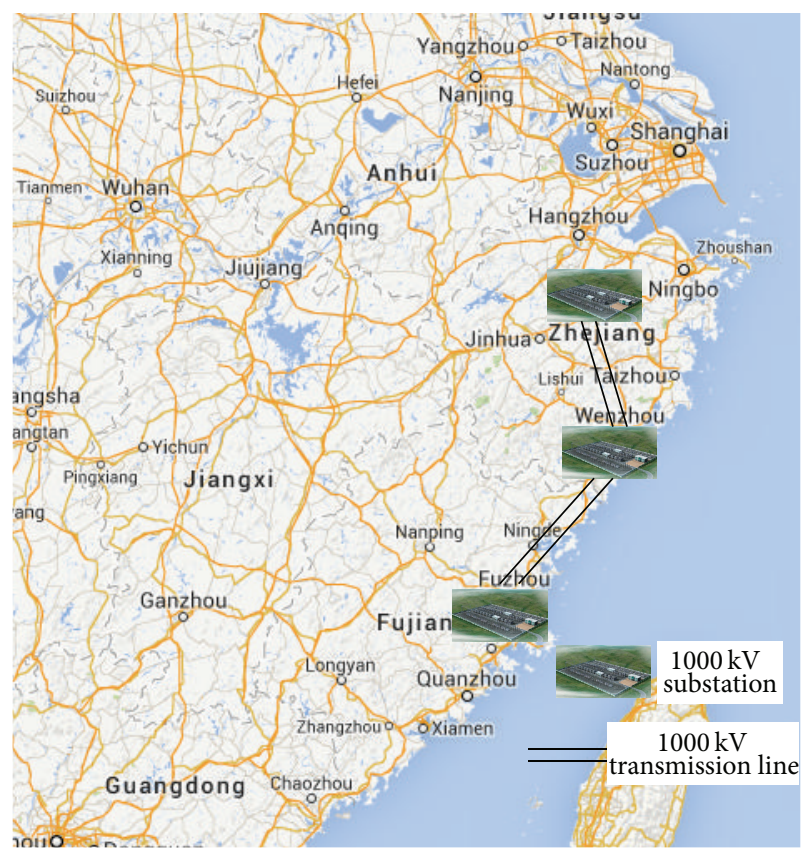

FIGURE 1: Geographical distribution of "Zhejiang-Fuzhou" UHV power transmission construction project.

into operation as planned, the power transmission bottleneck of East China Power System can be mitigated, and the safe and reliable operation of East China Power System can also be enhanced. Meanwhile, this project will make preparation for the future construction of UHV power grid.

This project is an important part of building the strong power grid of East China Power System, and it is also an AC/DC UHV power receiving platform for Zhejiang and Fujian power grid. This project plays a crucial role in supporting the safe and stable operation of power grid with UHVDC accessing the Zhejiang power grid. Meanwhile, it provides a main power exchange channel from Zhejiang to Fujian. More importantly, this construction project could fill the electricity gap of Zhejiang power grid and send out the power surplus of Fujian power grid during the "12th Five-Year Plan" period.

2.2. Project Characteristics. "Zhejiang-Fuzhou” UHV power transmission construction project has many special characteristics, just as follows.

2.2.1. Tight Time. According to the milestone plan, the UHV transformer substation project was commenced at the end of 2012, while the transmission line excavation was started in March 2013 and planned to be completed in December 2014. Due to the delaying of approval from the National Energy Administration and the relevant preresearching reports, it is impossible to reach the target of being approved at the end of this year, which will affect the subsequent project tasks, such as construction drawing design, project bidding, and contract signing. If the operation schedule remains unchanged, the effective project duration will be significantly shortened. 
2.2.2. Heavy Task. For this project, the land acquisition formality is very complicated with heavy workload and long process. At some substation sites, some farms and graves need to be relocated. Meanwhile, when the project workers carried out drilling and performed land acquisition, some villagers obstructed them by using the negative effect of electromagnetic radiation as an excuse. Moreover, the transmission line would pass through the areas with widely distributed mineral resources and numerous nature reserves, which will bring a negative impact on the project construction. The local folk custom is another big concern. What is more, the major equipment and materials for substations' and transmission lines' constructions need take long time and huge workload to manufacture, which is quite likely to go beyond the production capacity of domestic equipment manufacturing enterprises.

2.2.3. Difficult Construction. The construction of "ZhejiangFuzhou" UHV power transmission construction project will face many difficulties. The substation project will encounter large earthwork cutting-filling and massive piling constructions. The installed equipment is miscellaneous, and both the installation and testing standards are strict. The equipment transportation is difficult, and many roads and bridges need to be broadened and reinforced. The geological feature and foundation type along the project line are quite complex, and the required construction technique level is high. The terrain along the project line is undulate with high altitude, so it is difficult to transport the tower construction materials. The project line crosses a large number of roads and rivers, which makes the construction more complicated.

2.2.4. Complicated Environment. There are many tasks of "Zhejiang-Fuzhou" UHV power transmission project, including project approval, feasibility study, design, start and completed acceptance, and so on. All these tasks face different external environments. Meanwhile, with the market opening and economic development in China, the numbers of policies and laws affecting the project construction are increasing. In China, the society is relatively stable and harmonious, but it is undeniable that there are still some problems and contradictions in some social areas, some of which are very serious that may adversely affect and even hinder this project construction if not handled properly. What is more, this project locates along the southeast coast where the geological conditions are quite complex with a lot of mountains and hills.

\section{Building the Risk Evaluation Index System}

Risk index identification is a basis for building the risk evaluation index system, which is the beginning of UHV power transmission construction project management. The goal of risk index identification is to identify the most important risk index. Commonly, the risk index could be identified by using Delphi method which relies on the perceptual knowledge and experience of a panel of experts.

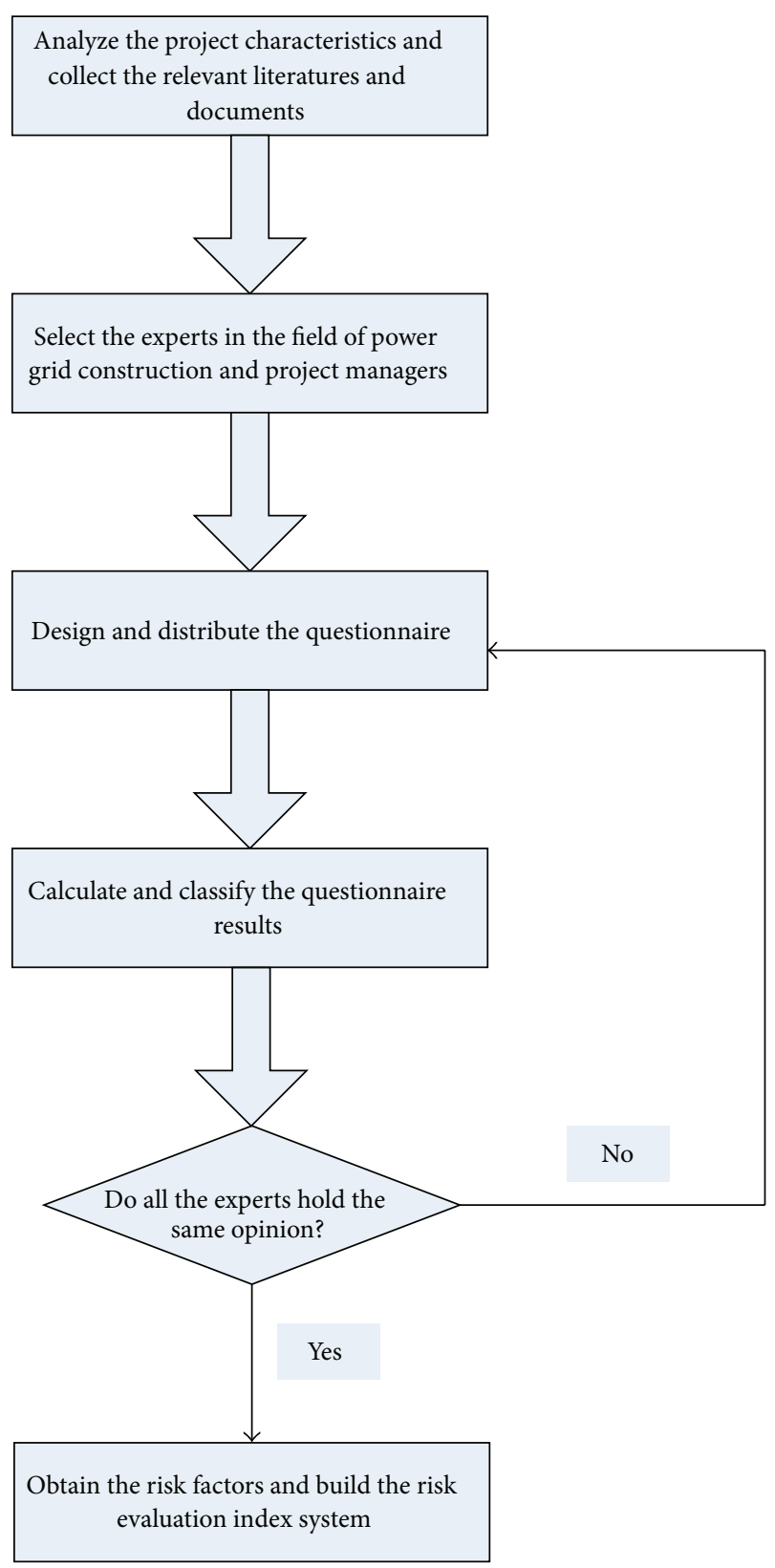

FIgURE 2: The procedure of risk index identification.

For "Zhejiang-Fuzhou” UHV power transmission construction project, based on the project characteristics as well as the relevant literatures and documents, the risk index of UHV power transmission construction project is identified by using Delphi method. The risk index identification procedure is shown in Figure 2.

The questionnaire regarding the risk of "ZhejiangFuzhou" UHV power transmission construction project includes more than 60 risk indicators. The experts and project managers conducted the questionnaire survey based on their knowledge and experience. By calculating the questionnaire results, 39 main risk indicators are selected for the "ZhejiangFuzhou" UHV power transmission construction project, which are called the second-level risk index. According to 
the characteristics of selected risk indicators and the expert advices, these 39 risk indicators are divided into "policy and law risk," "management risk," "technology risk," "natural environment risk," and "society risk," which are called the first-level risk criteria. Therefore, the risk evaluation index system of "Zhejiang-Fuzhou" UHV power transmission construction project is built, just as shown in Figure 3. From Figure 3, we can see that the risk evaluation index system contains 5 first-level risk criteria and 39 second-level risk indicators.

\section{Risk Evaluation on "Zhejiang-Fuzhou" UHV Power Transmission Construction Project Based on AHP and FCM}

The risk evaluation on "Zhejiang-Fuzhou” UHV power transmission construction project targets the safe and smooth operation of project. Risk evaluation is the combination of qualitative evaluation and quantitative evaluation. With regard to the UHV power transmission construction project, it is very hard to describe some risk factors with quantitative methods precisely; moreover, some risk factors are valued by experts with certain ambiguity. Therefore, the risk of UHV power transmission construction project needs to be evaluated by using a certain fuzzy evaluation method. In view of this characteristic, the fuzzy comprehensive evaluation (FCE) method is employed in this paper.

Determining the weight of each risk indicator is a difficult but crucial work when using FCE method to evaluate the risk of UHV power transmission construction project. Whether the index weight value is reasonable or not is directly related to the reliability of risk evaluation result. With regard to the risk evaluation of UHV power transmission construction project, it is a multiobjective issue that needs to consider many uncertain factors such as policy, society, and environment and so on; meanwhile, it also has a hierarchical structure. Therefore, the AHP method, which can effectively deal with the issue with a hierarchical structure and consider the wisdom and experience of expert to overcome the uncertain factors, is selected to determine the risk index weight.

The AHP is a multiobjective decision-making tool combining qualitative and quantitative analysis [12]. Its principle is as follows: firstly, divide the research issue into a hierarchical structure based on the interrelationship and membership between indicators; secondly, compare the importance of each indicator within the same layer with regard to the upper layer depending on the experience or intuition of experts; thirdly, obtain the importance of each indicator with regard to the final object through the hierarchical structure, and use the consistency test to justify the result accuracy $[13,14]$. The risk evaluation index system of UHV power transmission construction project is such a system that contains a multilevel hierarchical structure and exists correlation among indicators. Therefore, it is suitable to use AHP method to determine the weights of risk indicators.

FCE method, intended to quantify the vague factors which are difficult to quantify based on fuzzy mathematical
TABLE 1: The meaning of different risk types.

\begin{tabular}{ll}
\hline Risk types & Meaning \\
\hline High risk & $\begin{array}{l}\text { The occurrence probability of project risk is great, } \\
\text { and the risk occurrence will cause huge loss. }\end{array}$ \\
\hline Moderate risk & $\begin{array}{l}\text { The occurrence probability of project risk is } \\
\text { medium, and the risk occurrence will cause } \\
\text { general loss. }\end{array}$ \\
\hline Low risk & $\begin{array}{l}\text { The occurrence probability of project risk is low, } \\
\text { and the risk occurrence will cause small loss. }\end{array}$ \\
\hline
\end{tabular}

method, is a fuzzy bottom-up multicriteria decision making (MCDM) method $[15,16]$. As a specific application of fuzzy mathematics method, FCE method was proposed by the Chinese scholar P. Z. Wang. Considering the various factors associated with the evaluation system, the FCE method uses the fuzzy linear transformation principle and maximum membership degree principle to quantify the fuzzy indicators.

The framework of risk evaluation on "Zhejiang-Fuzhou" UHV power transmission construction project based on AHP and FCM method is shown in Figure 4.

The specific calculation steps for the risk evaluation on "Zhejiang-Fuzhou" UHV power transmission construction project based on AHP and FCE method are as follows.

4.1. Step 1: Building the Risk Evaluation Index System. The risk evaluation index system of "Zhejiang-Fuzhou" UHV power transmission construction project has been built in Section 3, just as shown in Figure 3.

4.2. Step 2: Determine the Evaluated Object and Evaluation Index Set. For the evaluated object $\mathbf{F}$, the evaluation index set $C=\left\{C_{i}\right\}(i=1,2, \ldots, n)$ is an entirety with intrinsic structure composing of the indicators that represent the characteristics of the evaluated object $\mathbf{F}$.

In this paper, the evaluated object $\mathbf{F}$ is the risk of "Zhejiang-Fuzhou" UHV power transmission construction project. The evaluation index set is composed of 39 risk indicators; namely, $C=\left\{C_{i}\right\}(i=1,2, \ldots, 39)$.

4.3. Step 3: Give the Remark Set. According to the evaluation standard and grade, the remark set $\mathbf{V}=\left[v_{1}, v_{2}, \ldots, v_{m}\right]$ can be made based on the opinions of experts and engineers considering the qualitative index and quantitative index together. The remark set $\mathbf{V}$ is composed of different risk grades, and $m$ in the remark set $\mathbf{V}$ represents the number of risk grades.

In this paper, according to the characteristics of "Zhejiang-Fuzhou" UHV power transmission construction project and the expertise suggestion in the field of power grid construction project, the evaluated risk is divided into three types, namely, "high risk," "moderate risk," and "low risk," the meanings of which are listed in Table 1. Thus, the remark set $\mathbf{V}$ can be made, namely, $\mathbf{V}=\left[v_{1}, v_{2}, v_{3}\right]$. 


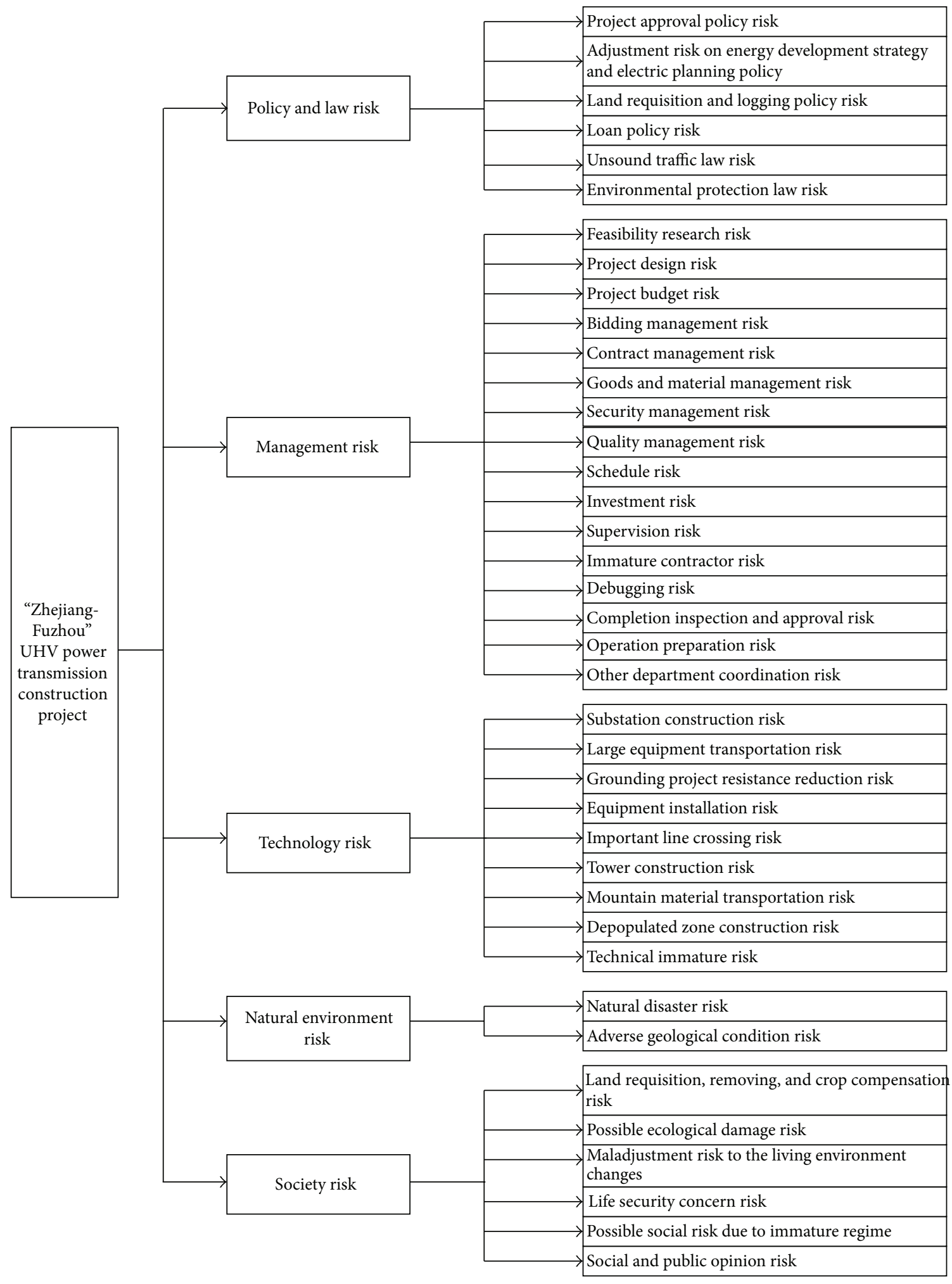

FIGURE 3: The risk evaluation index system of "Zhejiang-Fuzhou" UHV power transmission construction project. 


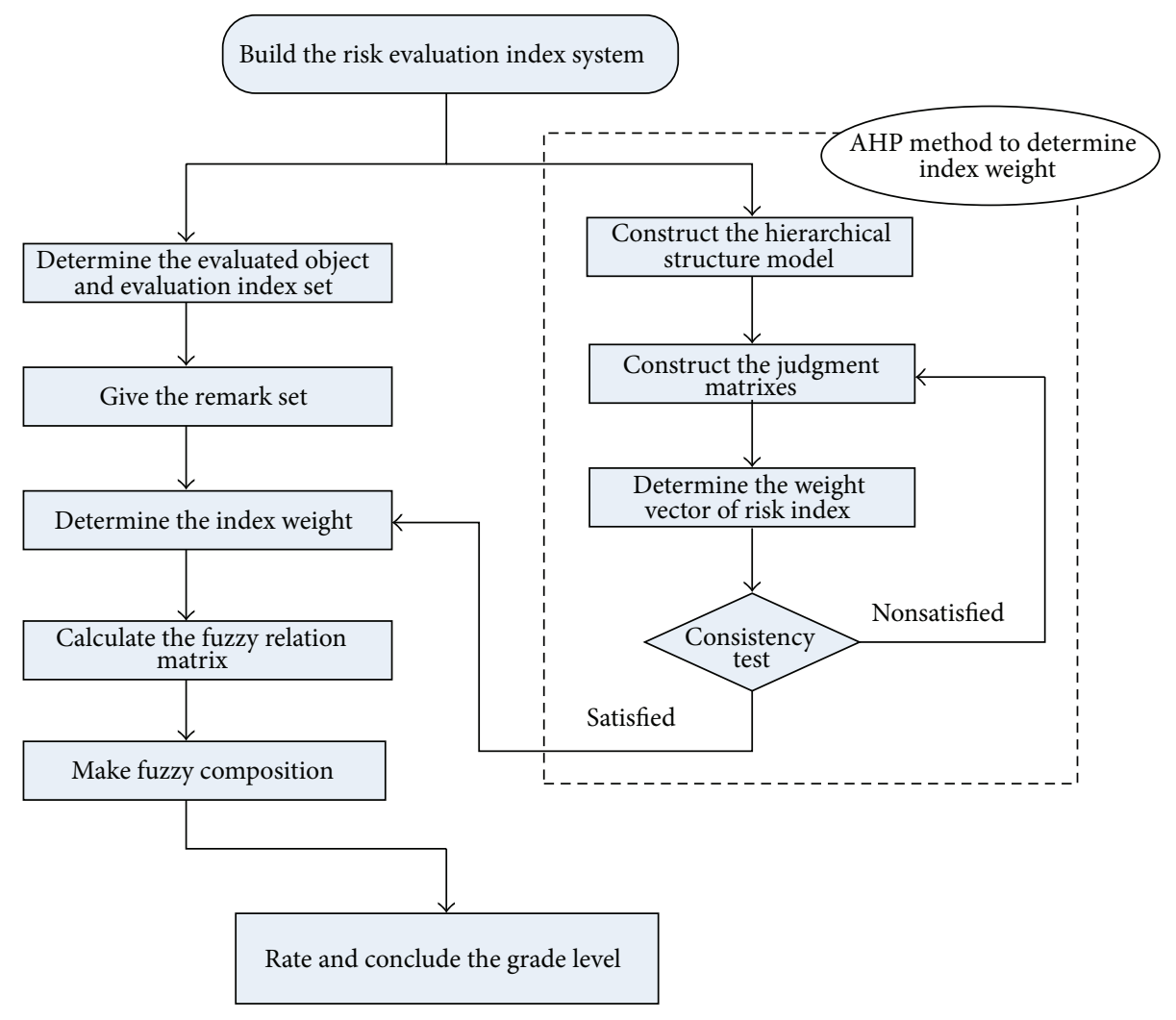

Figure 4: The framework of risk evaluation.

4.4. Step 4: Determine the Index Weight by Using AHP Method. In this paper, the AHP method is employed to determine the index weight. After building the evaluation index system, the local weight $W_{L}=\left\{w_{L 1}, w_{L 2}, \ldots, w_{L n}\right\}$ and global weight $W_{G}=\left\{w_{G 1}, w_{G 2}, \ldots, w_{G n}\right\}$ of indicators in index layer and the weight $W=\left\{w_{1}, w_{2}, \ldots, w_{h}\right\}$ of indicators in criteria layer can be calculated, where $\sum_{i=1}^{n} w_{G i}=1, \sum_{i=1}^{h} w_{i}=1,0 \leq w_{G i}$, $w_{i} \leq 1$.

4.4.1. Substep 1: Construct the Hierarchical Structure Model. According to the overall goal and characteristics of MCDM problem, the complex determination of index weight is decomposed and framed as a bottom-up hierarchical structure, which includes the goal layer, criteria layer, and index layer, just as shown in Figure 5.

In this paper, the risk evaluation index system contains 5 first-level risk criteria and 39 second-level risk indicators. Suppose $U=\left\{U_{1}, U_{2}, U_{3}, U_{4}, U_{5}\right\}=$ policy and law risk, management risk, technology risk, natural environment risk, society risks, $C=\left\{C_{1}, C_{2}, \ldots, C_{39}\right\}=$ project approval policy risk, adjustment risk on energy development strategy and electric planning policy, land requisition and logging policy risk, ..., social and public opinion risk. The bottomup hierarchical structure of risk evaluation of "ZhejiangFuzhou" UHV power transmission construction project is shown in Figure 6.

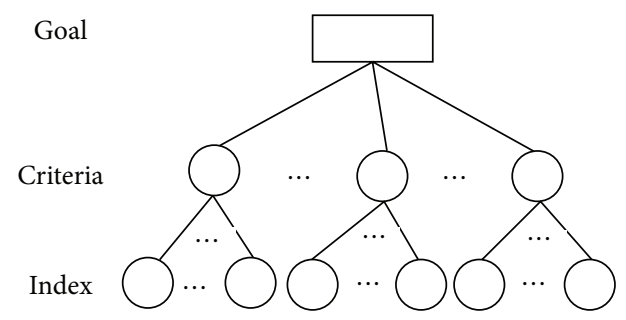

FIgURE 5: The hierarchical structure of AHP for determining the index weights.

4.4.2. Substep 2: Construct the Judgment Matrixes. The AHP uses the pairwise comparison method to construct the judgment matrixes for both criteria layer and index layer. The pairwise comparison is performed by using a nine-point scale which can convert human preference into quantitative value, just as shown in Table 2.

According to the analysis shown in Table 2, it shows that $a_{i j}>0, a_{i i}=1, a_{j i}=1 / a_{i j}$.

In this paper, after recognizing the judgments and opinions of experts and engineers related to UHV power transmission construction project according to the questionnaire result, the judgment matrixes of criteria layer and index layer by using the nine-point scale pair-wise comparison method are constructed, and the results are shown in Tables 3, 4, 5, 6, 7 , and 8. 


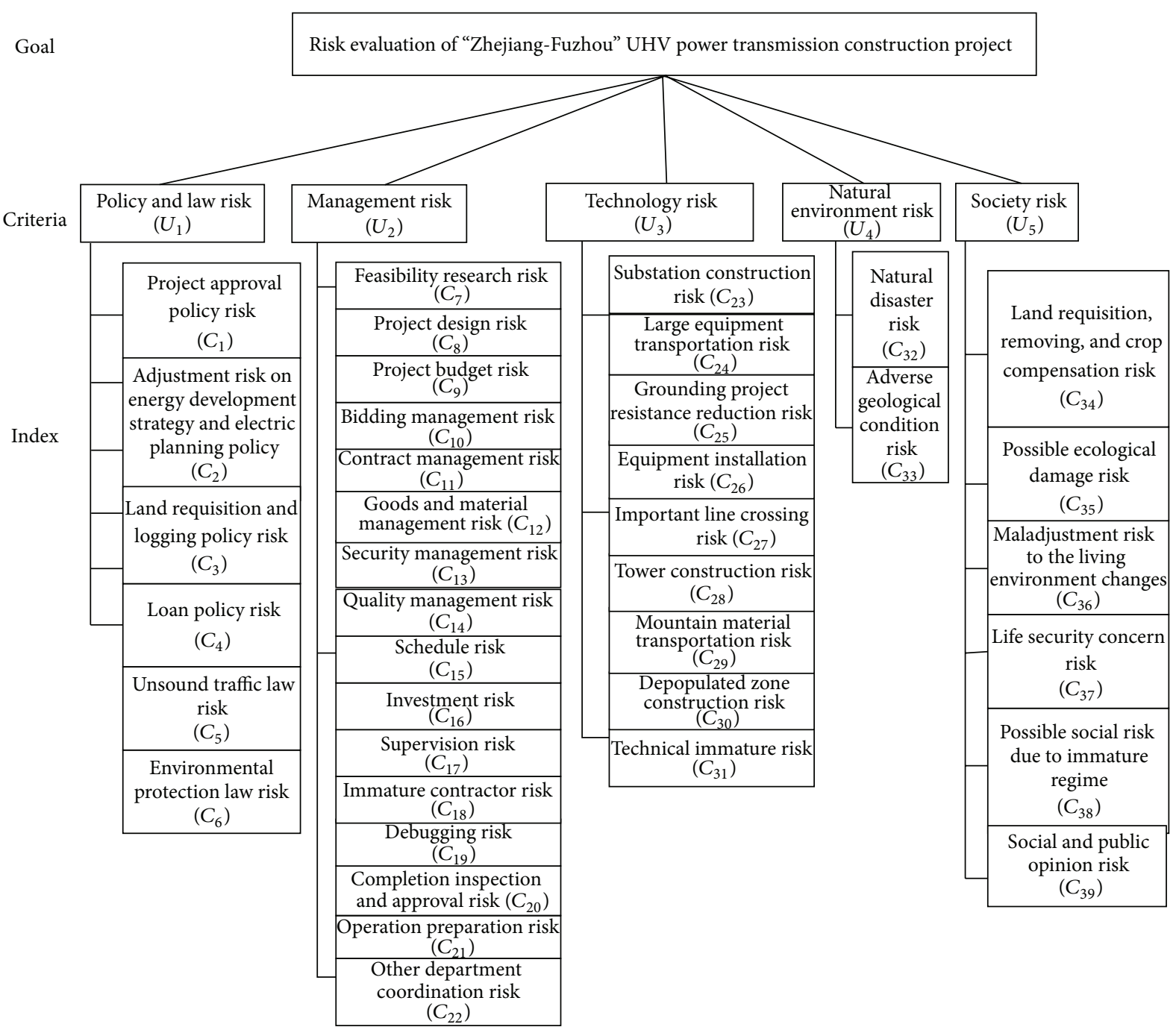

FIGURE 6: The hierarchical structure of risk evaluation.

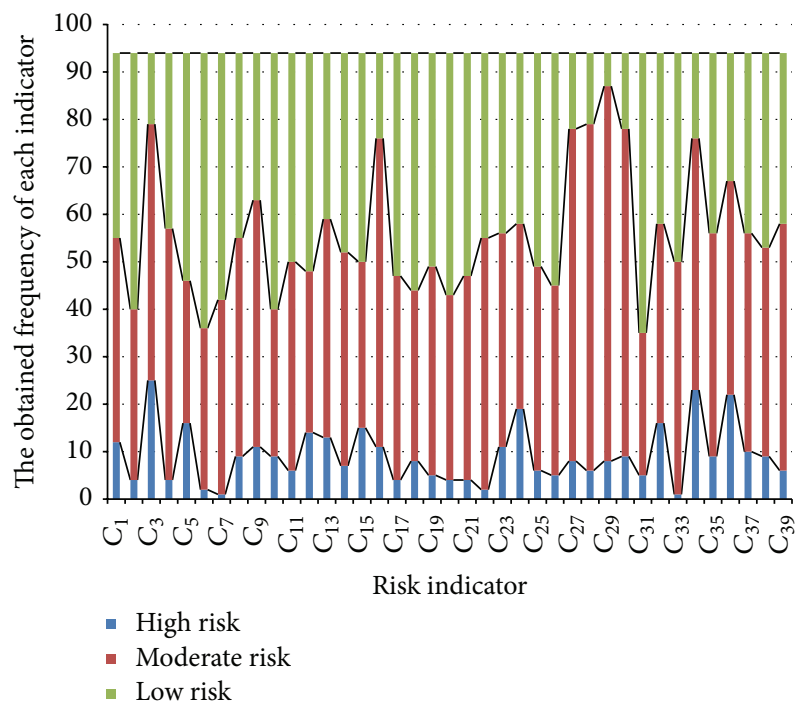

FIGURE 7: The obtained frequency of each indicator with different risk levels.
TABLE 2: Nine-point comparison scale.

\begin{tabular}{|c|c|}
\hline Scale $\left(a_{i j}\right)$ & Meaning \\
\hline 1 & Indicator $x_{i}$ is of the same importance as indicator $x_{j}$ \\
\hline 3 & $\begin{array}{l}\text { Indicator } x_{i} \text { is slightly more important than indicator } \\
x_{j}\end{array}$ \\
\hline 5 & $\begin{array}{l}\text { Indicator } x_{i} \text { is obviously more important than } \\
\text { indicator } x_{j}\end{array}$ \\
\hline 7 & $\begin{array}{l}\text { Indicator } x_{i} \text { is strongly more important than } \\
\text { indicator } x_{j}\end{array}$ \\
\hline 9 & $\begin{array}{l}\text { Indicator } x_{i} \text { is extremely more important than } \\
\text { indicator } x_{j}\end{array}$ \\
\hline $2,4,6,8$ & Middle value of above \\
\hline Reciprocal & $x_{i} / x_{j}=a_{i j}$, then $x_{j} / x_{i}=a_{j i}=1 / a_{i j}$. \\
\hline
\end{tabular}

4.4.3. Substep 3: Determine the Weight Vector of Risk Index. After the judgment matrix is obtained, the order weight vector of risk index can be calculated by using Eigenvalue 
TABLE 3: Pairwise comparison judgment matrixes and weights in criteria layer.

\begin{tabular}{lcccccc}
\hline & $U_{1}$ & $U_{2}$ & $U_{3}$ & $U_{4}$ & $U_{5}$ & Weight \\
\hline$U_{1}$ & 1.00 & 0.90 & 1.40 & 1.80 & 0.65 & 0.20 \\
$U_{2}$ & 1.11 & 1.00 & 1.50 & 1.65 & 0.70 & 0.22 \\
$U_{3}$ & 0.71 & 0.67 & 1.00 & 1.25 & 0.45 & 0.15 \\
$U_{4}$ & 0.56 & 0.61 & 0.80 & 1.00 & 0.40 & 0.12 \\
$U_{5}$ & 1.54 & 1.43 & 2.22 & 2.50 & 1.00 & 0.31 \\
\hline
\end{tabular}

TABLE 4: Judgment matrixes and weights of "policy and law risk" criteria.

\begin{tabular}{lccccccc}
\hline Policy and law risk & $C_{1}$ & $C_{2}$ & $C_{3}$ & $C_{4}$ & $C_{5}$ & $C_{6}$ & Local weight \\
\hline$C_{1}$ & 1.00 & 3.00 & 0.50 & 2.50 & 0.80 & 3.50 & 0.20 \\
$C_{2}$ & 0.33 & 1.00 & 0.20 & 0.90 & 0.33 & 1.20 & 0.07 \\
$C_{3}$ & 2.00 & 5.00 & 1.00 & 4.50 & 2.00 & 5.20 & 0.37 \\
$C_{4}$ & 0.40 & 1.11 & 0.22 & 1.00 & 0.30 & 1.60 & 3.20 \\
$C_{5}$ & 1.25 & 3.00 & 0.50 & 3.33 & 1.00 & 0.08 & 0.22 \\
$C_{6}$ & 0.29 & 0.83 & 0.19 & 0.63 & 0.31 & 0.06 \\
\hline \multicolumn{7}{c}{} \\
\hline
\end{tabular}

TABLE 5: Judgment matrixes and weights of "management risk" criteria.

\begin{tabular}{|c|c|c|c|c|c|c|c|c|c|c|c|c|c|c|c|c|c|}
\hline $\begin{array}{l}\text { Management } \\
\text { risk }\end{array}$ & $C_{7}$ & $C_{8}$ & $C_{9}$ & $C_{10}$ & $C_{11}$ & $C_{12}$ & $C_{13}$ & $C_{14}$ & $C_{15}$ & $C_{16}$ & $C_{17}$ & $C_{18}$ & $C_{19}$ & $C_{20}$ & $C_{21}$ & $C_{22}$ & Local weight \\
\hline$C_{7}$ & 1.00 & 0.33 & 0.29 & 0.50 & 0.67 & 0.25 & 0.28 & 0.50 & 0.24 & 0.28 & 0.91 & 0.56 & 0.77 & 0.83 & 0.83 & 0.91 & 0.03 \\
\hline$C_{8}$ & 3.00 & 1.00 & 0.91 & 1.20 & 1.50 & 0.67 & 0.71 & 1.30 & 0.40 & 0.67 & 2.50 & 1.80 & 2.00 & 2.20 & 2.30 & 2.50 & 0.07 \\
\hline$C_{9}$ & 3.50 & 1.10 & 1.00 & 1.50 & 2.50 & 0.83 & 1.00 & 1.50 & 0.83 & 1.00 & 2.50 & 2.00 & 2.60 & 2.80 & 2.80 & 3.00 & 0.09 \\
\hline$C_{10}$ & 2.00 & 0.83 & 0.67 & 1.00 & 1.20 & 0.50 & 0.56 & 1.00 & 0.45 & 0.67 & 1.50 & 1.20 & 1.50 & 1.60 & 1.60 & 1.80 & 0.06 \\
\hline$C_{11}$ & 1.50 & 0.67 & 0.40 & 0.83 & 1.00 & 0.33 & 0.45 & 0.77 & 0.29 & 0.40 & 1.30 & 0.83 & 1.10 & 1.20 & 1.20 & 1.30 & 0.04 \\
\hline$C_{12}$ & 4.00 & 1.50 & 1.20 & 2.00 & 3.00 & 1.00 & 1.20 & 1.80 & 0.83 & 1.20 & 3.20 & 2.00 & 2.80 & 3.00 & 3.00 & 3.20 & 0.11 \\
\hline$C_{13}$ & 3.60 & 1.40 & 1.00 & 1.80 & 2.20 & 0.83 & 1.00 & 1.60 & 0.83 & 1.00 & 2.80 & 1.80 & 2.20 & 2.30 & 2.30 & 2.50 & 0.09 \\
\hline$C_{14}$ & 2.00 & 0.77 & 0.67 & 1.00 & 1.30 & 0.56 & 0.63 & 1.00 & 0.50 & 0.56 & 1.80 & 1.10 & 1.50 & 1.60 & 1.60 & 1.80 & 0.06 \\
\hline$C_{15}$ & 4.20 & 2.50 & 1.20 & 2.20 & 3.50 & 1.20 & 1.20 & 2.00 & 1.00 & 1.20 & 4.00 & 2.20 & 3.00 & 3.20 & 3.20 & 3.50 & 0.12 \\
\hline$C_{16}$ & 3.60 & 1.50 & 1.00 & 1.50 & 2.50 & 0.83 & 1.00 & 1.80 & 0.83 & 1.00 & 2.50 & 1.80 & 2.20 & 2.40 & 2.40 & 2.50 & 0.09 \\
\hline$C_{17}$ & 1.10 & 0.40 & 0.40 & 0.67 & 0.77 & 0.31 & 0.36 & 0.56 & 0.25 & 0.40 & 1.00 & 0.67 & 0.83 & 0.91 & 0.91 & 1.00 & 0.03 \\
\hline$C_{18}$ & 1.80 & 0.56 & 0.50 & 0.83 & 1.20 & 0.50 & 0.56 & 0.91 & 0.45 & 0.56 & 1.50 & 1.00 & 1.50 & 1.60 & 1.60 & 1.80 & 0.05 \\
\hline$C_{19}$ & 1.30 & 0.50 & 0.38 & 0.67 & 0.91 & 0.36 & 0.45 & 0.67 & 0.33 & 0.45 & 1.20 & 0.67 & 1.00 & 1.20 & 1.20 & 1.10 & 0.04 \\
\hline$C_{20}$ & 1.20 & 0.45 & 0.36 & 0.63 & 0.83 & 0.33 & 0.43 & 0.63 & 0.31 & 0.42 & 1.10 & 0.63 & 0.83 & 1.00 & 1.00 & 1.10 & 0.04 \\
\hline$C_{21}$ & 1.20 & 0.43 & 0.36 & 0.63 & 0.83 & 0.33 & 0.43 & 0.63 & 0.31 & 0.42 & 1.10 & 0.63 & 0.83 & 1.00 & 1.00 & 1.10 & 0.04 \\
\hline$C_{22}$ & 1.10 & 0.4 & 0.33 & 0.56 & 0.77 & 0.31 & 0.40 & 0.56 & 0.29 & 0.40 & 1.00 & 0.56 & 0.91 & 0.91 & 0.91 & 1.00 & 0.03 \\
\hline \multicolumn{18}{|c|}{$\lambda_{\max }=16.055, \mathrm{CI}=0.003697, \mathrm{CR}=0.0023<0.1$} \\
\hline
\end{tabular}

method. The eigenvector of judgment matrix with the maximum eigenvalue is the weight vector of risk index, which denotes the relative importance of indicators in the same level with regard to the indicators in the upper layer. The weight vector of risk index is the relative importance of indicators with regard to the upper layer indicator, which is also called the local weight.

In this paper, the weights of indictors in criteria layer and local weights of indicators in index layer are calculated, which are lists in Tables 3-8, respectively. 
TABLE 6: Judgment matrixes and weights of "technology risk" criteria.

\begin{tabular}{lccccccccccc}
\hline Technology risk & $C_{23}$ & $C_{24}$ & $C_{25}$ & $C_{26}$ & $C_{27}$ & $C_{28}$ & $C_{29}$ & $C_{30}$ & $C_{31}$ & Local weight \\
\hline$C_{23}$ & 1.00 & 0.67 & 2.22 & 2.22 & 1.25 & 1.67 & 1.11 & 1.00 & 2.50 & 0.14 \\
$C_{24}$ & 1.50 & 1.00 & 2.86 & 3.33 & 1.67 & 2.50 & 1.43 & 1.33 & 3.33 & 0.20 \\
$C_{25}$ & 0.45 & 0.35 & 1.00 & 1.11 & 0.59 & 0.80 & 0.56 & 0.50 & 1.25 & 0.07 \\
$C_{26}$ & 0.45 & 0.30 & 0.90 & 1.00 & 0.56 & 0.71 & 0.50 & 0.45 & 1.11 & 0.06 \\
$C_{27}$ & 0.80 & 0.60 & 1.70 & 1.80 & 1.00 & 1.33 & 0.83 & 0.80 & 2.00 & 0.11 \\
$C_{28}$ & 0.60 & 0.40 & 1.25 & 1.40 & 0.75 & 1.00 & 0.67 & 0.67 & 1.43 & 0.09 \\
$C_{29}$ & 0.90 & 0.70 & 1.80 & 2.00 & 1.20 & 1.50 & 1.00 & 0.91 & 2.22 & 0.13 \\
$C_{30}$ & 1.00 & 0.75 & 2.00 & 2.20 & 1.25 & 1.50 & 1.10 & 1.00 & 2.50 & 0.14 \\
$C_{31}$ & 0.40 & 0.30 & 0.80 & 0.90 & 0.50 & 0.70 & 0.45 & 0.40 & 1.00 & 0.06 \\
\hline
\end{tabular}

TABLE 7: Judgment matrixes and weights of "natural environment risk" criteria.

\begin{tabular}{lccc}
\hline Natural environment risk & $C_{32}$ & $C_{33}$ & Local weight \\
\hline$C_{32}$ & 1 & 1.8 & 0.64 \\
$C_{33}$ & 0.56 & 1 & 0.36 \\
\hline \multicolumn{4}{c}{$\lambda_{\max }=2, \mathrm{CI}=0, \mathrm{CR}=0<0.1$} \\
\hline
\end{tabular}

4.4.4. Substep 4: Consistency Test. The consistency of relative importance judgment on each indicator made by experts and engineers is the key prerequisite for using the AHP to determine the weights of risk indicators. Hence, it is very necessary to test the consistency of judgment matrix. When the consistency of judgment matrix is satisfied, the maximum eigenvalue of the judgment matrix $\lambda_{\max }$ should be equal to the number of indicators, which are related to two consistency test indices, namely CI and CR.

Consistency index (CI), which measures the divergence of judgment matrix away from the consistency, is defined as follows:

$$
\mathrm{CI}=\frac{\lambda_{\max }-n}{n-1}
$$

where $n$ represents the number of indices.

Thus, the consistency ratio (CR) is defined as follows:

$$
\mathrm{CR}=\frac{\mathrm{CI}}{\mathrm{RI}}
$$

$\mathrm{RI}$ is the random consistency index which is the average value of eigenvalues obtained by calculating the judgment matrix for more than 500 times. The value of RI is given in Table 9.

If $\mathrm{CR}<0.1$, the weight vector is acceptable; otherwise, the modification of the pairwise judgment matrix is needed.

As listed in the last row in Tables 3-8, respectively, all the pairwise comparison judgment matrixes satisfy the consistency test.

4.4.5. Substep 5: Calculate the Index Weight. The global weight of each indicator can be determined by multiplying the local weight of the indicator with the weight of upper layer indicator which locates in the parent node above it.

The local and global weights of each risk indicator in index layer and the weight of each indicator in criteria layer are calculated, which are listed in Table 10.

4.5. Step 5: Calculate the Fuzzy Relation Matrix. According to the statistical result of the questionnaire by using a certain mathematical method, such as frequency-based method and weighted average method, the first-level fuzzy relation matrix $\mathbf{R}$ can be calculated as follows

$$
\mathbf{R}=\left(r_{i j}\right)_{n \times m}=\left[\begin{array}{cccc}
r_{11} & r_{12} & \ldots & r_{1 m} \\
r_{21} & r_{22} & \ldots & r_{2 m} \\
\vdots & \vdots & \vdots & \vdots \\
r_{n 1} & r_{n 2} & \ldots & r_{n m}
\end{array}\right]
$$

where $r_{i j}$ is the membership degree of the $j$ th remark in remark set $\mathbf{V}$ for the indicator $i, i=1,2, \ldots, n ; j=$ $1,2, \ldots, m, n$ is the number of indices, and $m$ is the number of risk grades in remark set $\mathbf{V}$. Different rows in the fuzzy relation matrix $\mathbf{R}$ reflect the different membership degrees of evaluated object subject to fuzzy set of each grade considering different evaluation indices.

The frequency-based method is used to establish the fuzzy relation matrix in this paper, the principle of which is if the number of experts and engineers who judge the "high risk," "moderate risk," and "low risk" is $m_{1}, m_{2}$, and $m_{3}$ respectively, then the set $\left(m_{1} / \sum_{k=1}^{3} m_{k}, m_{2} / \sum_{k=1}^{3} m_{k}, m_{3} / \sum_{k=1}^{3} m_{k}\right)$ is the membership set of the evaluation index. The obtained frequency of each indicator with different risk grades is listed in Figure 7.

Thus, the first-level fuzzy relation matrix $\mathbf{R}$ can be calculated just as follows

$$
R_{1}=\left[\begin{array}{lll}
0.1277 & 0.4574 & 0.4149 \\
0.4255 & 0.3830 & 0.5745 \\
0.2660 & 0.5745 & 0.1595 \\
0.0426 & 0.5638 & 0.3936 \\
0.1702 & 0.3192 & 0.5106 \\
0.0213 & 0.3617 & 0.6170
\end{array}\right] ;
$$




$$
\begin{aligned}
& {\left[\begin{array}{lll}
0.0106 & 0.4362 & 0.5532
\end{array}\right]} \\
& \begin{array}{llll}
0.0957 & 0.4894 & 0.4149
\end{array} \\
& \begin{array}{lll}
0.1170 & 0.5532 & 0.3298
\end{array} \\
& \begin{array}{llll}
0.0957 & 0.3298 & 0.5745
\end{array} \\
& \begin{array}{lll}
0.0638 & 0.4681 & 0.4681
\end{array} \\
& \begin{array}{lll}
0.1489 & 0.3617 & 0.4894
\end{array} \\
& \begin{array}{lll}
0.1383 & 0.4894 & 0.3723
\end{array} \\
& R_{2}= \\
& \begin{array}{lll}
0.0745 & 0.4787 & 0.4468
\end{array} \\
& \begin{array}{lll}
0.1596 & 0.3723 & 0.4681 \\
0.1170 & 0.6915 & 0.1915
\end{array} \\
& \begin{array}{lll}
0.0426 & 0.4574 & 0.5000
\end{array} \\
& \begin{array}{llll}
0.0851 & 0.3830 & 0.5319
\end{array} \\
& \begin{array}{lll}
0.0532 & 0.4681 & 0.4787
\end{array} \\
& \begin{array}{lll}
0.0426 & 0.4149 & 0.5425
\end{array} \\
& \begin{array}{lll}
0.0426 & 0.4574 & 0.5000
\end{array} \\
& {\left[\begin{array}{lll}
0.0213 & 0.5638 & 0.4149
\end{array}\right]} \\
& R_{3}=\left[\begin{array}{lll}
0.1170 & 0.4787 & 0.4043 \\
0.2021 & 0.4149 & 0.3830 \\
0.0638 & 0.4575 & 0.4787 \\
0.0532 & 0.4255 & 0.5213 \\
0.0851 & 0.7447 & 0.1702 \\
0.0638 & 0.7766 & 0.1596 \\
0.0851 & 0.8404 & 0.0745 \\
0.0958 & 0.7340 & 0.1702 \\
0.0532 & 0.3191 & 0.6277
\end{array}\right] ; \\
& R_{4}=\left[\begin{array}{lll}
0.1702 & 0.4468 & 0.3830 \\
0.0106 & 0.5213 & 0.4681
\end{array}\right] \text {; } \\
& R_{5}=\left[\begin{array}{lll}
0.2447 & 0.5638 & 0.1915 \\
0.0957 & 0.5000 & 0.4043 \\
0.2340 & 0.4787 & 0.2872 \\
0.1064 & 0.4894 & 0.4042 \\
0.0957 & 0.4681 & 0.4362 \\
0.0638 & 0.5532 & 0.3830
\end{array}\right] \text {. }
\end{aligned}
$$

4.6. Step 6: Make Fuzzy Composition. Synthesize the firstlevel fuzzy relation matrix $\mathbf{R}$ with the local weight $W_{L}$, and then the membership matrix $B_{i}$ could be obtained, which is call the first-level fuzzy comprehensive evaluation matrix:

$$
B_{i}=W_{L} \mathrm{o} R=\left(b_{i 1}, b_{i 2}, \ldots, b_{i m}\right) .
$$

Due to the hierarchical structure of the evaluation index system, the second-level fuzzy relation matrix $R^{\prime}$ needs to be calculated:

$$
R^{\prime}=\left[\begin{array}{c}
B_{1} \\
B_{2} \\
\vdots \\
B_{k}
\end{array}\right]=\left[\begin{array}{cccc}
b_{11} & b_{12} & \cdots & b_{1 m} \\
b_{21} & b_{22} & \cdots & b_{2 m} \\
\cdots & \cdots & \cdots & \cdots \\
b_{k 1} & b_{k 2} & \cdots & b_{k m}
\end{array}\right]
$$

Then, combined with the weight matrix $W$, the secondlevel fuzzy comprehensive evaluation matrix $\mathbf{B}$ can be calculated as follows:

$$
\mathbf{B}=W \mathrm{o} R^{\prime}=\left(b_{1}, b_{2}, \ldots, b_{m}\right)
$$

where $b_{m}$ is the membership degree of the $m$ th remark in remark set $\mathbf{V}$.

In this paper, the first-level fuzzy comprehensive evaluation matrix $B_{i}$ is calculated as follows:

$$
\begin{aligned}
& B_{1}=W_{L 1} \mathrm{o} R_{1} \\
& =\left(\begin{array}{llllll}
0.20 & 0.07 & 0.37 & 0.08 & 0.22 & 0.06
\end{array}\right) \\
& \mathrm{O}\left[\begin{array}{lll}
0.1277 & 0.4574 & 0.4149 \\
0.4255 & 0.3830 & 0.5745 \\
0.2660 & 0.5745 & 0.1595 \\
0.0426 & 0.5638 & 0.3936 \\
0.1702 & 0.3192 & 0.5106 \\
0.0213 & 0.3617 & 0.6170
\end{array}\right] \\
& =\left(\begin{array}{lll}
0.1690 & 0.4679 & 0.3631
\end{array}\right) \text {. }
\end{aligned}
$$

Similarly, we can obtain

$$
\begin{aligned}
& B_{2}=\left(\begin{array}{lll}
0.1005 & 0.4585 & 0.4310
\end{array}\right), \\
& B_{3}=\left(\begin{array}{lll}
0.1073 & 0.5905 & 0.3022
\end{array}\right), \\
& B_{4}=\left(\begin{array}{lll}
0.1128 & 0.4736 & 0.4136
\end{array}\right), \\
& B_{5}=\left(\begin{array}{lll}
0.1710 & 0.5133 & 0.3157
\end{array}\right) .
\end{aligned}
$$

Then, we obtain the second-level fuzzy relation matrix $R^{\prime}$ :

$$
R^{\prime}=\left[\begin{array}{lll}
0.1690 & 0.4679 & 0.3631 \\
0.1005 & 0.4585 & 0.4310 \\
0.1073 & 0.5905 & 0.3022 \\
0.1128 & 0.4736 & 0.4136 \\
0.1710 & 0.5133 & 0.3157
\end{array}\right]
$$

The second-level fuzzy comprehensive evaluation matrix B can be calculated as follows

$$
\begin{aligned}
& \mathbf{B}=W_{\mathrm{o}} R^{\prime} \\
& =\left(\begin{array}{lllll}
0.20 & 0.22 & 0.15 & 0.12 & 0.31
\end{array}\right) \\
& \text { o }\left[\begin{array}{lll}
0.1690 & 0.4679 & 0.3631 \\
0.1005 & 0.4585 & 0.4310 \\
0.1073 & 0.5905 & 0.3022 \\
0.1128 & 0.4736 & 0.4136 \\
0.1710 & 0.5133 & 0.3157
\end{array}\right] \\
& =\left(\begin{array}{lll}
0.1385 & 0.4990 & 0.3603
\end{array}\right) \text {. }
\end{aligned}
$$

4.7. Step 7: Rate and Conclude the Grade Level. According to the maximum membership degree principle, when $b_{i 0}=$ $\max b_{i}(1 \leq i \leq m)$, we can judge that the evaluated object belongs to the $i_{0}$ grade.

In this paper, since $b_{2}=\max b_{i}(1 \leq i \leq 3)=$ 0.4990 , it is shown that the risk grade of "Zhejiang-Fuzhou" UHV power transmission construction project belongs to "moderate," which means the occurrence probability of this project risk is medium and the risk occurrence will cause general loss. So it is necessary for the project managers to 
TABLE 8: Judgment matrixes and weights of "society risk" criteria.

\begin{tabular}{|c|c|c|c|c|c|c|c|}
\hline Society risk & $C_{34}$ & $C_{35}$ & $C_{36}$ & $C_{37}$ & $C_{38}$ & $C_{39}$ & Local weight \\
\hline$C_{34}$ & 1 & 2.3 & 1.2 & 1.8 & 2 & 3 & 0.29 \\
\hline$C_{35}$ & 0.43 & 1 & 0.5 & 0.8 & 0.9 & 1.3 & 0.12 \\
\hline$C_{36}$ & 0.83 & 2 & 1 & 1.5 & 1.7 & 2.5 & 0.24 \\
\hline$C_{37}$ & 0.56 & 1.25 & 0.67 & 1 & 1.1 & 1.7 & 0.16 \\
\hline$C_{38}$ & 0.5 & 0.11 & 0.59 & 0.91 & 1 & 1.5 & 0.10 \\
\hline$C_{39}$ & 0.33 & 0.77 & 0.4 & 0.59 & 0.67 & 1 & 0.09 \\
\hline \multicolumn{8}{|c|}{$\lambda_{\max }=5.9109, \mathrm{CI}=-0.0178, \mathrm{CR}=-0.0141<0.1$} \\
\hline
\end{tabular}

TABLE 9: The value of RI.

\begin{tabular}{ccccccccccccccc}
\hline$n$ & 1,2 & 3 & 4 & 5 & 6 & 7 & 8 & 9 & 10 & 11 & 12 & 13 & 14 & 15 \\
\hline $\mathrm{RI}$ & 0 & 0.52 & 0.89 & 1.12 & 1.26 & 1.36 & 1.41 & 1.45 & 1.49 & 1.52 & 1.54 & 1.56 & 1.57 & 1.58 \\
\hline
\end{tabular}

carry out some specific risk control measures to make the construction of this project run successfully.

At the meantime, valuing the evaluation result of indicators in criteria layer in centesimal form can help project managers to analyze the project risk more efficiently. Suppose the comment set $\mathbf{V}=\left[v_{1}, v_{2}, v_{3}\right]=\left\{\begin{array}{lll}90 & 50 & 10\end{array}\right\}$, and then the centesimal value of each indicator in criteria layer can be calculated as follows

$$
\begin{aligned}
U_{1} & =0.1690 \times 90+0.4679 \times 50+0.3631 \times 10 \\
& =42.2383, \\
U_{2} & =0.1005 \times 90+0.4585 \times 50+0.4310 \times 10 \\
& =36.2830, \\
U_{3} & =0.1073 \times 90+0.5905 \times 50+0.3022 \times 10 \\
& =42.2, \\
U_{4} & =0.1128 \times 90+0.4736 \times 50+0.4136 \times 10 \\
& =37.9660, \\
U_{5} & =0.1710 \times 90+0.5133 \times 50+0.3157 \times 10 \\
& =44.2085 .
\end{aligned}
$$

The centesimal value $(U)$ of risk evaluation of "ZhejiangFuzhou" UHV power transmission construction project can be calculated as

$$
\begin{aligned}
U & =0.1385 \times 90+0.4990 \times 50+0.3603 \times 10 \\
& =41.0205 .
\end{aligned}
$$

Figure 8 compares the centesimal value of each indicator in criteria layer, and we can see

$$
U_{5}>U_{1}>U_{3}>U>U_{4}>U_{2} .
$$

Therefore, the centesimal value of "society risk" is the highest, followed by "policy and law risk," "technology risk," "natural environmental risk," and "management risk." The centesimal values of both "management risk" and "natural

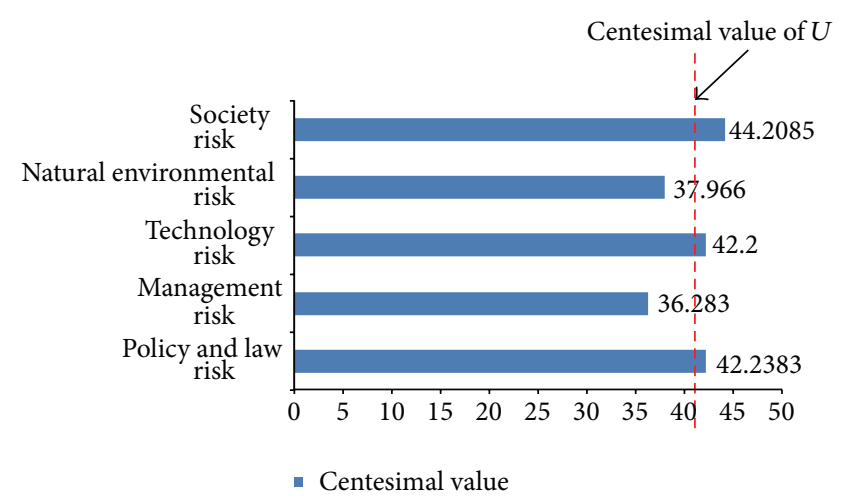

FIGURE 8: Centesimal value of each indicator in criteria layer.

environmental risk" are lower than that of the project $U$, while the centesimal values of other three indicators are larger than that of the project $U$. The criteria "Society risk," "policy and law risk," and "technology risk" should be paid more attention in the risk management and control for "Zhejiang-Fuzhou" UHV power transmission construction project.

\section{Risk Control Recommendations}

According to the risk evaluation result, we should pay more attention to "society risk," "policy and law risk," and "technology risk." The specific risk control recommendations are as follows.

\subsection{Risk Control Recommendations for "Society Risk"}

(1) Before and during the construction of "ZhejiangFuzhou" UHV power transmission project, the propaganda work should be done in the form of TV, radio, newspapers, brochures, and so on. The construction significance and engineering safety knowledge related to this project should be propagandized in order to eliminate the worries from society followers and local villagers about this UHV power transmission project. 
TABLE 10: The weight of risk indicators.

\begin{tabular}{|c|c|c|c|c|}
\hline \multicolumn{2}{|c|}{ Criteria layer } & \multicolumn{3}{|c|}{ Index layer } \\
\hline Indicator & Weight $(W)$ & Indicator & Local weight $\left(W_{L}\right)$ & Global weight $\left(W_{G}\right)$ \\
\hline \multirow{6}{*}{ Policy and law risk $\left(U_{1}\right)$} & \multirow{6}{*}{0.20} & $C_{1}$ & 0.20 & 0.0400 \\
\hline & & $\mathrm{C}_{2}$ & 0.07 & 0.0140 \\
\hline & & $C_{3}$ & 0.37 & 0.0740 \\
\hline & & $C_{4}$ & 0.08 & 0.0160 \\
\hline & & $C_{5}$ & 0.22 & 0.0440 \\
\hline & & $\mathrm{C}_{6}$ & 0.06 & 0.0120 \\
\hline \multirow{16}{*}{ Management risk $\left(U_{2}\right)$} & \multirow{16}{*}{0.22} & $C_{7}$ & 0.03 & 0.0066 \\
\hline & & $C_{8}$ & 0.07 & 0.0154 \\
\hline & & $C_{9}$ & 0.09 & 0.0198 \\
\hline & & $C_{10}$ & 0.06 & 0.0132 \\
\hline & & $C_{11}$ & 0.04 & 0.0088 \\
\hline & & $C_{12}$ & 0.11 & 0.0242 \\
\hline & & $C_{13}$ & 0.09 & 0.0198 \\
\hline & & $C_{14}$ & 0.06 & 0.0132 \\
\hline & & $C_{15}$ & 0.12 & 0.0264 \\
\hline & & $C_{16}$ & 0.09 & 0.0198 \\
\hline & & $C_{17}$ & 0.03 & 0.0066 \\
\hline & & $C_{18}$ & 0.05 & 0.0110 \\
\hline & & $C_{19}$ & 0.04 & 0.0088 \\
\hline & & $C_{20}$ & 0.04 & 0.0088 \\
\hline & & $C_{21}$ & 0.04 & 0.0088 \\
\hline & & $C_{22}$ & 0.03 & 0.0066 \\
\hline \multirow{9}{*}{ Technology risk $\left(U_{3}\right)$} & \multirow{9}{*}{0.15} & $C_{23}$ & 0.14 & 0.0210 \\
\hline & & $C_{24}$ & 0.20 & 0.0300 \\
\hline & & $C_{25}$ & 0.07 & 0.0105 \\
\hline & & $C_{26}$ & 0.06 & 0.0090 \\
\hline & & $C_{27}$ & 0.11 & 0.0165 \\
\hline & & $C_{28}$ & 0.09 & 0.0135 \\
\hline & & $C_{29}$ & 0.13 & 0.0195 \\
\hline & & $C_{30}$ & 0.14 & 0.0210 \\
\hline & & $C_{31}$ & 0.06 & 0.0090 \\
\hline \multirow{2}{*}{ Natural environment risk $\left(U_{4}\right)$} & \multirow{2}{*}{0.12} & $C_{32}$ & 0.64 & 0.0768 \\
\hline & & $C_{33}$ & 0.36 & 0.0432 \\
\hline \multirow{6}{*}{ Society risk $\left(U_{5}\right)$} & \multirow{6}{*}{0.31} & $C_{34}$ & 0.29 & 0.0899 \\
\hline & & $C_{35}$ & 0.12 & 0.0372 \\
\hline & & $C_{36}$ & 0.24 & 0.0744 \\
\hline & & $C_{37}$ & 0.16 & 0.0496 \\
\hline & & $C_{38}$ & 0.1 & 0.0310 \\
\hline & & $C_{39}$ & 0.09 & 0.0279 \\
\hline
\end{tabular}

(2) Grid company should try to sign a contract with local government, which strives to make the local government be responsible for land requisition, house relocation, and crop compensation. Grid company can also set up a working group to coordinate with the local government. The determination of land compensation standards not only abides by the relevant laws and regulations, but also takes the opinions of local masses into consideration.
(3) The terrain and ecological resources along the project line should be fully understood when selecting the optimal route. Having some experienced practitioners on the team and considering the local customs are better for the route determination. During the project construction, the water and soil loss as well as deforestation should be reduced as far as possible. When the project is finished, the vegetation should be restored timely. 
(4) Keep close touch with the local government and public security organization in order to strengthen the security of project construction; the "mass incidents" such as petitions, demagoguism, and demonstration should be paid close attention, and some related measures such as propaganda and negotiation should be taken timely; strengthen the project construction management and perform civilized construction, and reduce the negative impacts on local residents to a minimum.

\subsection{Risk Control Recommendations for "Policy and Law Risk"}

(1) The project-related personnel, especially the project managers, should carefully study the policies and laws related to land management, deforestation, loan, and environmental protection, and the related legal counsel should be engaged in order to reduce the legal risk during the project construction.

(2) Strengthen the research on the policies and guidance documents related to energy development and planning.

(3) Strengthen the communication with the government department to improve the efficiency of project examination and approval.

(4) Because the size and weight of UHV equipment are bigger and heavier, the traffic laws and regulations should be carefully studied to avoid the conflict related to UHV equipment transportation. Transportation limitations should be taken into consideration when selecting the UHV equipment, and survey on the transport route is very necessary.

\subsection{Risk Control Recommendations for "Technology Risk"}

(1) Track the meteorological information timely and arrange the construction plan according to the weather condition; some necessary measures should be taken to protect the equipment from rainwater, such as building the temporary drain and increasing the pumping equipment.

(2) The earth-rock excavation should keep a reasonable proportion based on the quantity calculation.

(3) For waterway transport, due to the constant change of shipping lane, the simulation navigation should be performed six months in advance to ensure the transportation safety.

(4) Measure the earth resistivity and design the grounding grid; establish special subjects to study the impacts of ground resistance on UHV GIS equipment and the operation of control and protection system.

(5) Design the crossing construction based on different crossing facilities to reduce the risk and difficulty; when crossing the electricity lines, the crossing scheme should be designed at the design stage and take the terrain characteristic along the project line into consideration.

(6) The material transport plan should take weather and transportation environment into consideration; optimize the use of different transportation facilities, and make the fullest use of crawler-transporter vehicle and cableway.

\section{Conclusions}

In this paper, a hybrid evaluation model based on AHP and FCE method is implemented to evaluate the risk of "Zhejiang-Fuzhou" UHV power transmission construction project. This hybrid evaluation model takes full advantages of AHP and FCE method. After the risk evaluation index system is built, the AHP is used to determine the index weight, and FCE method is used to evaluate the project risk. Finally, the specific risk control recommendations are proposed. The main results of risk evaluation of "Zhejiang-Fuzhou" UHV power transmission construction project are as follows.

(1) The risk grade of "Zhejiang-Fuzhou" UHV power transmission construction project belongs to "moderate," which indicates the occurrence probability of project risk is medium and the risk occurrence will cause general loss.

(2) "Society risk" has the highest level, and the next is "policy and law risk," "technique risk," "natural environmental risk," and "management risk," respectively; "society risk," "policy and law risk" and "technology risk" should be paid more attention in the risk management and control for "Zhejiang-Fuzhou" UHV power transmission construction project.

(3) Risk control recommendations for main risk criteria which include society risk, policy and law risk and technology risk are proposed.

(4) This hybrid evaluation model is feasible and effective, which can effectively evaluate the risk of UHV power transmission construction project.

\section{Conflict of Interests}

The authors declare that there is no conflict of interests regarding the publication of this paper.

\section{Acknowledgments}

This study is supported by the Humanity and Social Science project of the Ministry of Education of China (Project no. 11YJA790217) and the National Natural Science Foundation of China (Project no. 71373076).

\section{References}

[1] J. P. Liu, D. X. Niu, and X. H. Song, "The energy supply and demand pattern of China: a review of evolution and sustainable development," Renewable and Sustainable Energy Reviews, vol. 25, pp. 220-228, 2013. 
[2] C. C. Lin, C. H. Yang, and J. Z. Shyua, "A comparison of innovation policy in the smart grid industry across the pacific: china and the USA," Energy Policy, vol. 57, pp. 119-132, 2013.

[3] M. Bolinger and R. Wiser, "A comparative analysis of business structures suitable for farmer-owned wind power projects in the United States," Energy Policy, vol. 34, no. 14, pp. 1750-1761, 2006.

[4] S. Grassi, N. Chokani, and R. S. Abhari, "Large scale technical and economical assessment of wind energy potential with a GIS tool: case study Iowa," Energy Policy, vol. 45, pp. 73-85, 2012.

[5] M. Hellström, I. Ruuska, K. Wikström, and D. Jåfs, "Project governance and path creation in the early stages of Finnish nuclear power projects," International Journal of Project Management, vol. 31, no. 5, pp. 712-723, 2013.

[6] P. Baumann and G. Stevanella, "Fish passage principles to be considered for medium and large dams: the case study of a fish passage concept for a hydroelectric power project on the Mekong mainstem in Laos," Ecological Engineering, vol. 48, pp. 79-85, 2012.

[7] W. Amatayakul and G. Berndes, "Determining factor for the development of CDM biomass power projects," Energy for Sustainable Development, vol. 16, pp. 197-203, 2012.

[8] J. L. Liu, Q. X. Li, and Y. H. Wang, "Risk analysis in ultra deep scientific drilling project-A fuzzy synthetic evaluation approach," International Journal of Project Management, vol. 31, no. 3, pp. 449-458, 2013.

[9] A. Badri, S. Nadeau, and A. Gbodossou, "A new practical approach to risk management for underground mining project in Quebec," Journal of Loss Prevention in the Process Industries, vol. 26, no. 6, pp. 1145-1158, 2013.

[10] J. B. Song, D. R. Song, X. Q. Zhang, and Y. Sun, "Risk identification for PPP waste-to-energy incineration projects in China," Energy Policy, vol. 61, pp. 953-962, 2013.

[11] Y. Hu, J. F. Du, X. Z. Zhang et al., "An integrative framework for intelligent software project risk planning," Decision Support Systems, vol. 55, no. 4, pp. 927-937, 2013.

[12] T. L. Saaty, The Analytic Hierarchy Process, McGraw-Hill, New York, NY, USA, 1980.

[13] M. P. Amiri, "Project selection for oil-fields development by using the AHP and fuzzy TOPSIS methods," Expert Systems with Applications, vol. 37, no. 9, pp. 6218-6224, 2010.

[14] H. Z. Li and S. Guo, "External economies evaluation of wind power engineering project based on analytic hierarchy process and matter-element extension model," Mathematical Problems in Engineering, vol. 2013, Article ID 848901, 11 pages, 2013.

[15] F.-G. Chen, H.-L. Yao, and W.-G. Shi, "Application of fuzzy and synthetic judgment to risk assessment of dammed lake," Journal of Shanghai Jiaotong University, vol. 45, no. 1, pp. 67-75, 2011.

[16] K. Fang, B.-F. He, M. Yang, and Z.-C. Wang, "Application of fuzzy comprehensive evaluation method to CENS," Journal of Harbin Institute of Technology, vol. 43, no. 5, pp. 30-36, 2011. 


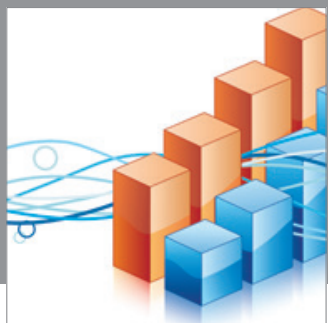

Advances in

Operations Research

mansans

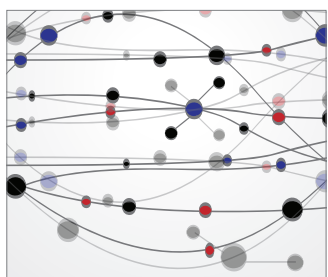

The Scientific World Journal
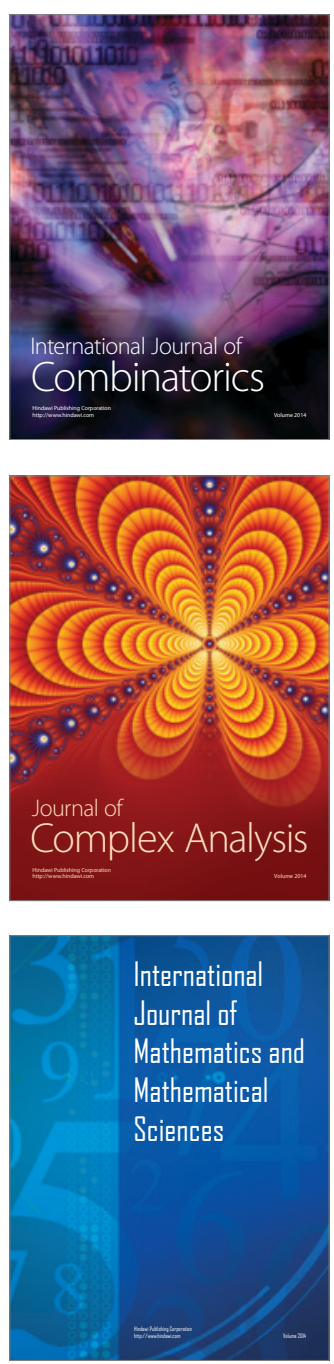
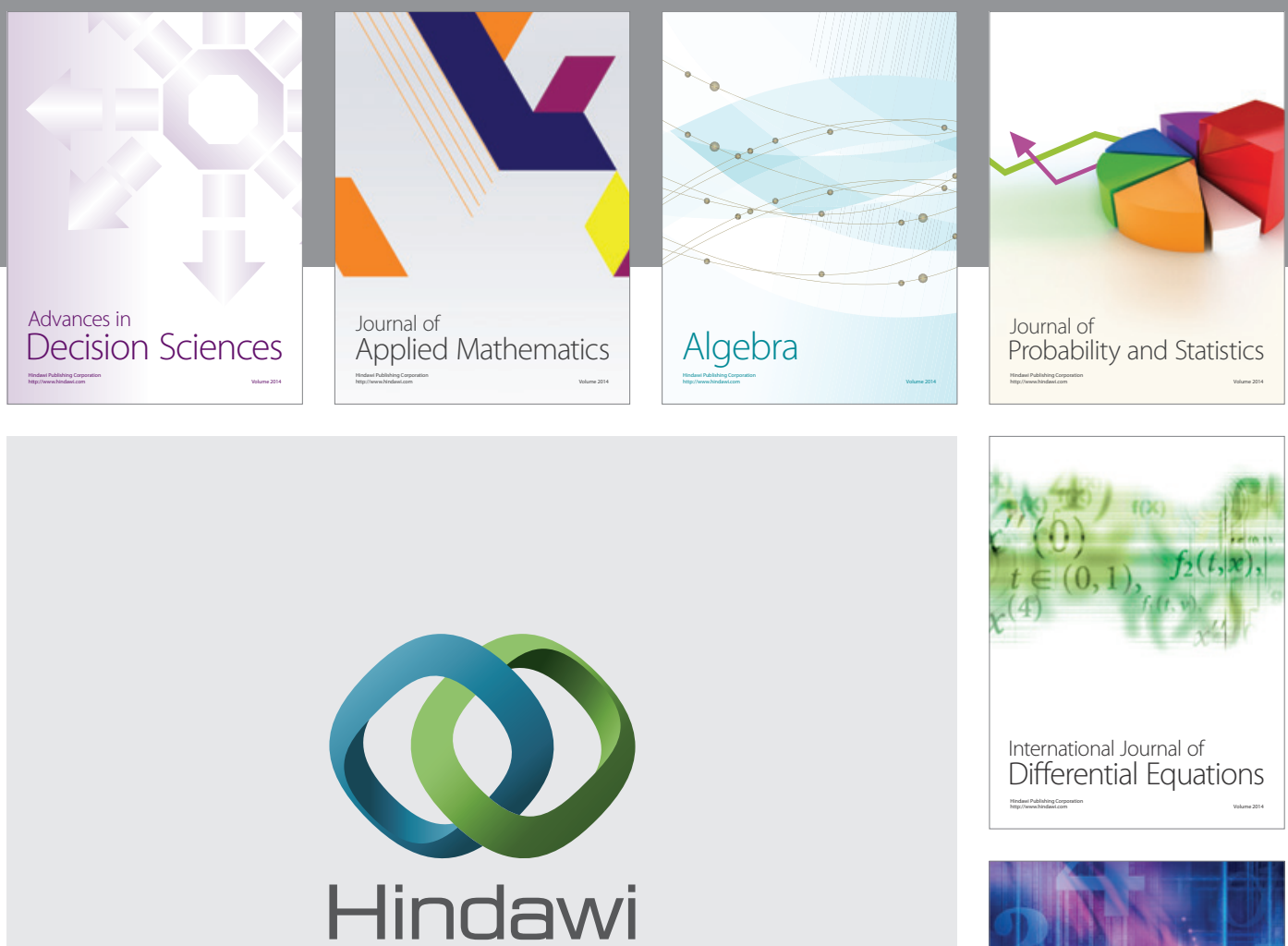

Submit your manuscripts at http://www.hindawi.com
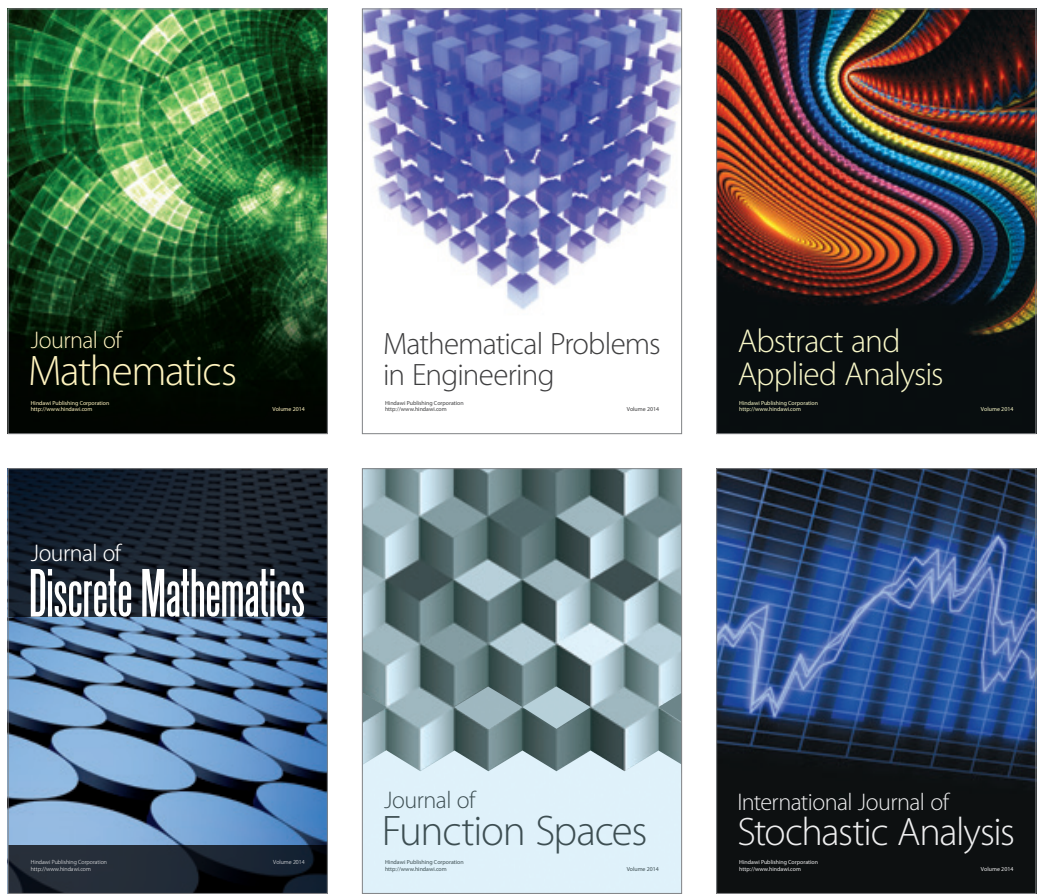

Journal of

Function Spaces

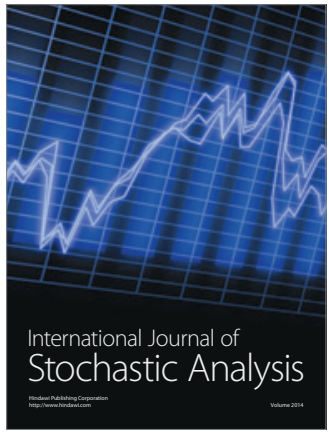

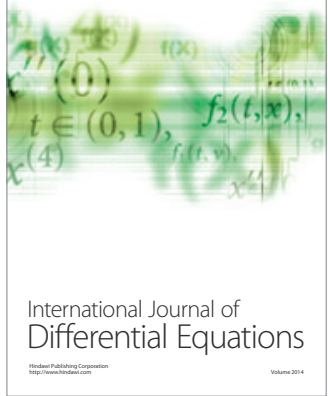
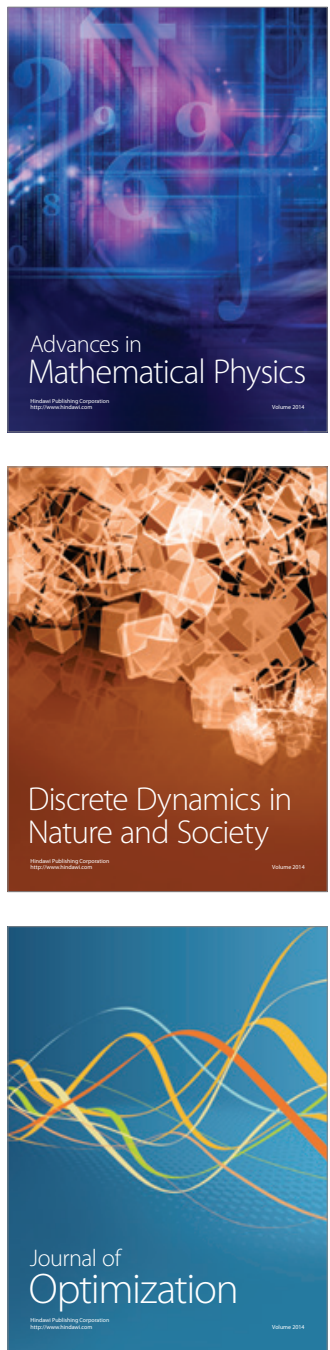